\title{
THOUGHTS OF A PERCEPTIVE BLUE JAY
}

Photos by DOUGLAS A. SCHMEISER, College of Law, Sub Post Office 6, University of Saskatchewan, Saskatoon, Saskatchewan. S7N OWO

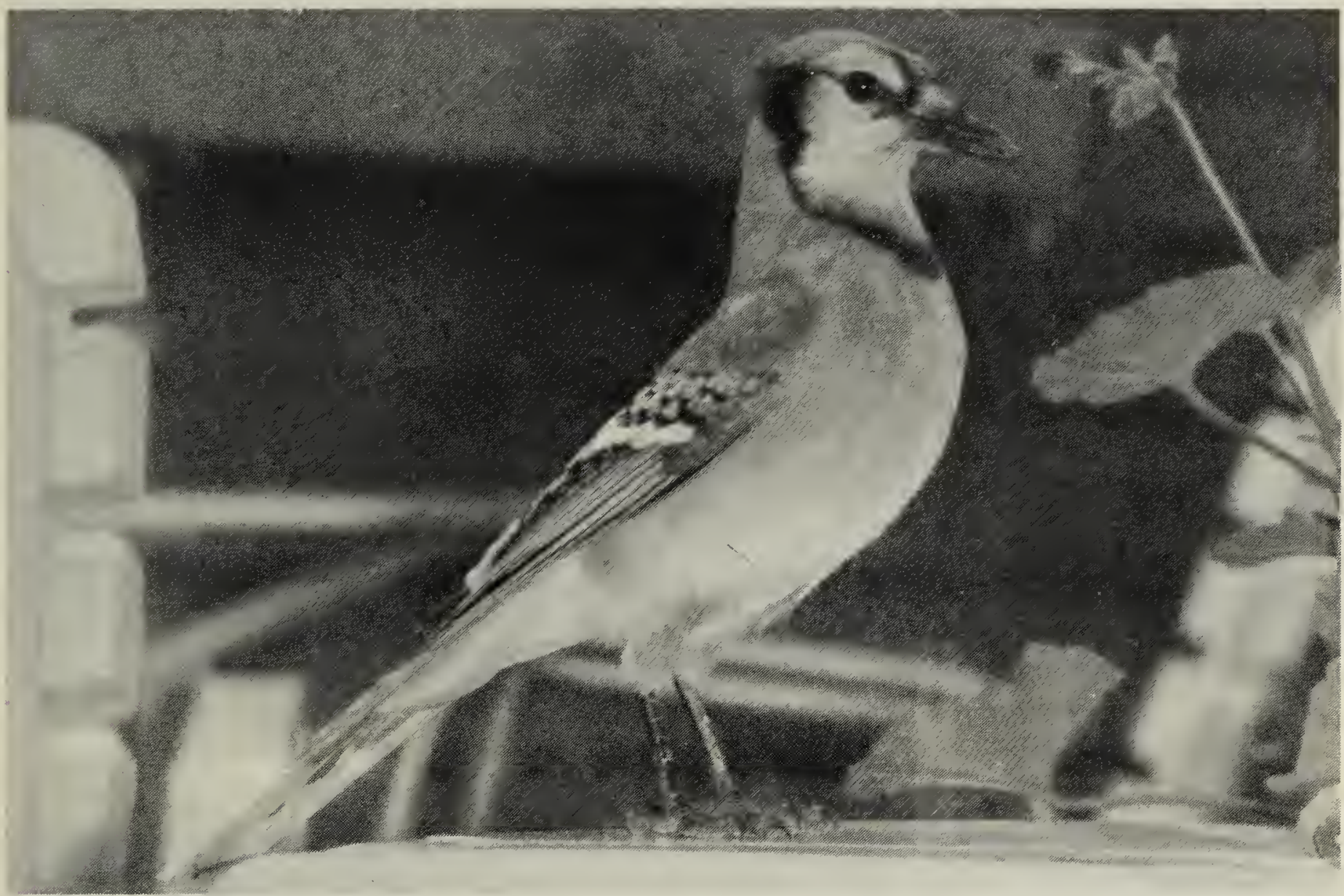

Well! Well! Well!

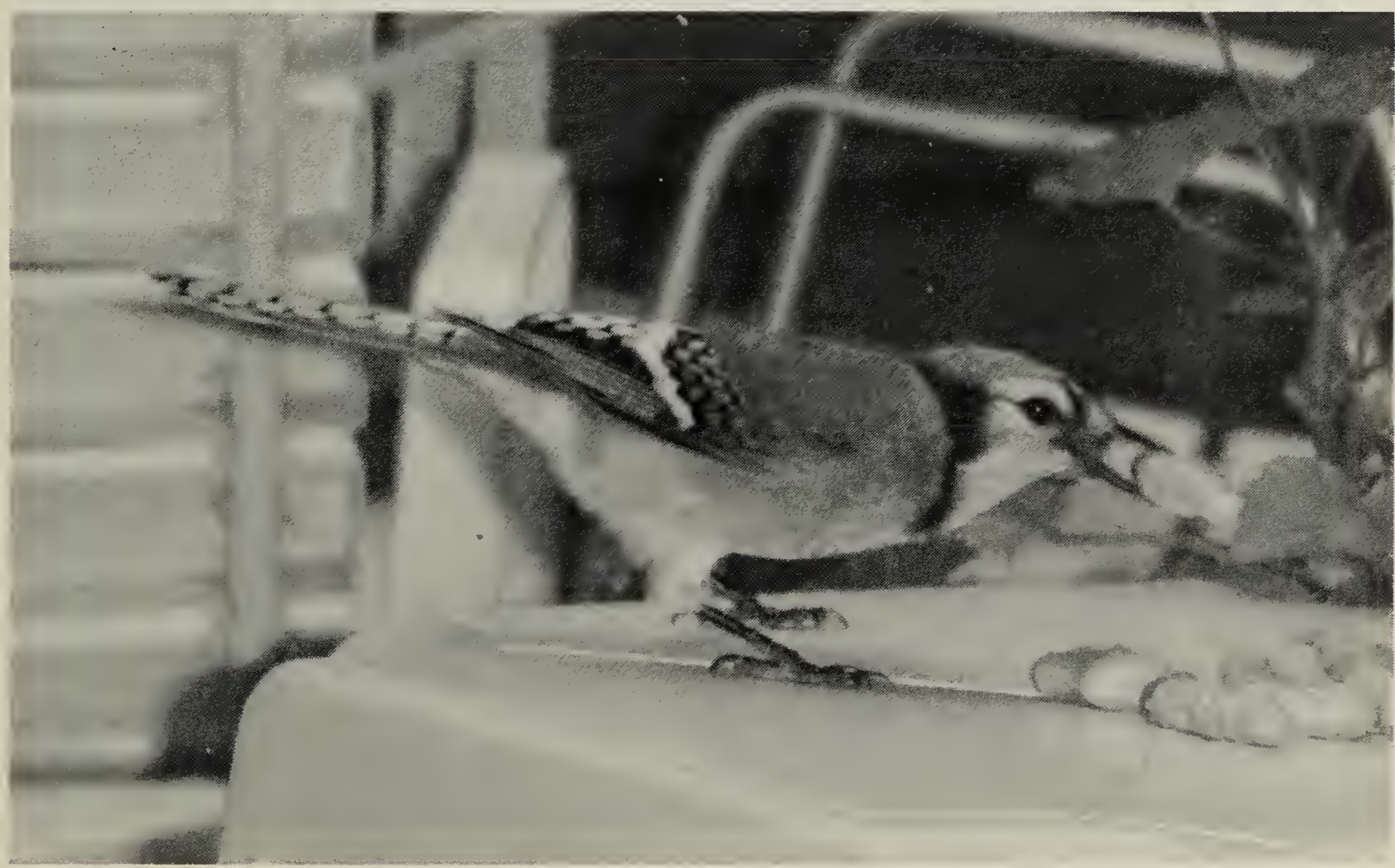

Umm! Umm! Good! 


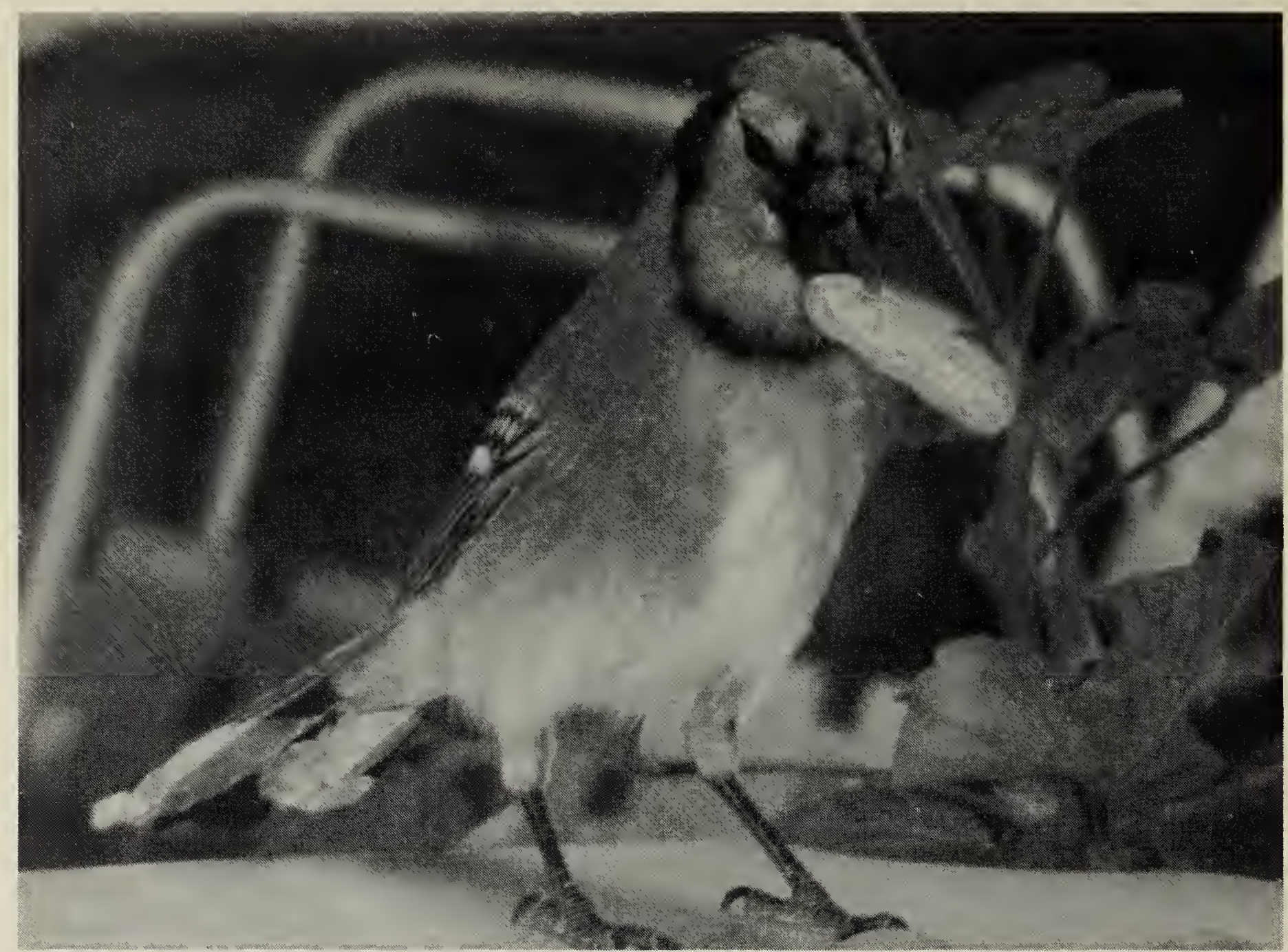

Deeee-lec-table!

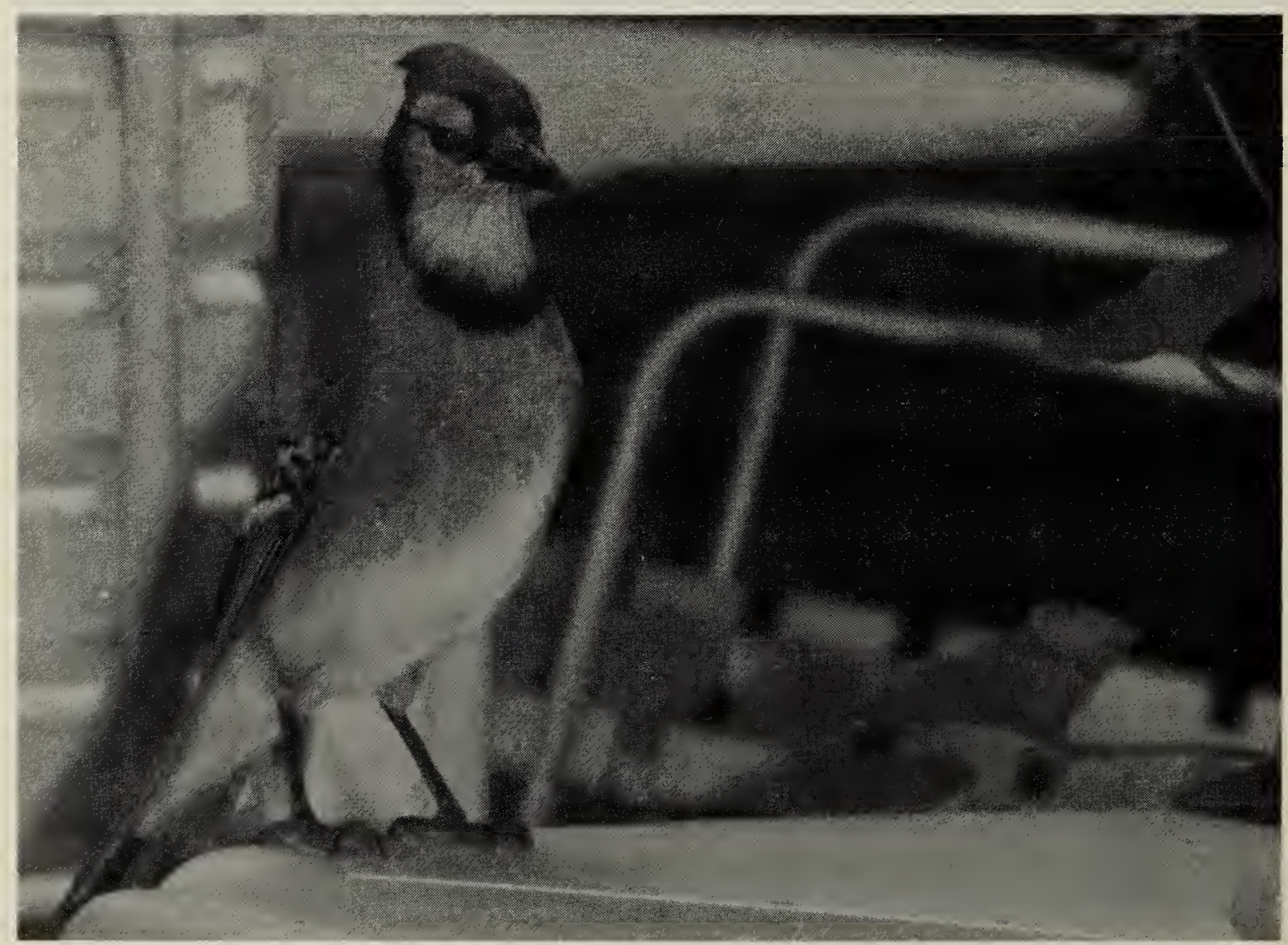

Just green seedless? No way! 